Methodological aspects and updates of computational models

\title{
On the current needs in European decision support tools for contaminated areas
}

\author{
K.G. ANDERSSON
}

\begin{abstract}
As part of the ongoing European project NERIS-TP, a revision has been made of some parameters influencing dose estimates in the European emergency management decision support systems RODOS and ARGOS. On the basis of survey data, the estimates of the time fractions typically spent indoors and outdoors over longer time periods have been revised. On the basis of measurement data, also new values for the natural ventilation rate governing early ingression of contaminants into dwellings have been derived for different parts of Europe. Other potential parameterisation improvements for the decision support systems are discussed.
\end{abstract}

Keywords: Emergency preparedness/decision support/RODOS/ARGOS/indoor

\section{Introduction}

One of the strategic objectives of the European NERIS platform on preparedness for nuclear and radiological emergency response and recovery, which was launched in 2010, is to promote exchange of information and views, and to identify needs for further technological developments in the field. An on-going RTD activity supported by the European Commission deals with the practical implementation of the recently revised ICRP recommendations, e.g., through adaptation of the existing decision support systems ARGOS and RODOS. Examples are given of the outcome of this activity with respect to parameterisation in the decision support systems of indoor/outdoor air exchange and time budgets (the parameterisation so far applied in RODOS and ARGOS for these has not been based on European survey data), considering recommendations on new data and regional implementation, as well as the novel reference person concept. Other needs for technological developments for the decision support systems with respect to dose estimation are briefly discussed.

Center for Nuclear Technologies, Technical University of Denmark (Risø Campus), DK-4000 Roskilde, Denmark. 


\section{Methods and results}

\subsection{Time budgets for estimation of external dose in contaminated inhabited areas}

It is clear from the kerma rate calculations of Meckbach et al. (1988) that the fraction of time spent outdoors will generally have a large effect on external dose received from an airborne deposit of radionuclides, e.g., following a large nuclear power plant accident. If people are not removed permanently from the area, the major part of the external dose in such scenarios would be received over a long time period, where people staying in the area are likely to have resumed their traditional habits (a nuclear accident may possibly change long term habits, but this is impossible to predict, and the best assumption for the purpose of future dose estimates will therefore be a return to traditional habits). For instance for $662 \mathrm{keV}$ gamma radiation $\left({ }^{137} \mathrm{Cs}\right)$, the kerma rate in outdoor locations in the standard RODOS/ARGOS environment with multistorey house blocks is according to Meckbach et al.'s calculations generally hundreds of times greater than the corresponding in indoor locations. Even in a housing environment with buildings of prefabricated parts (thin walls made of wood, gypsum and glass-wool), the outdoor kerma rate for the same gamma energy would be around a factor of 2 higher than that in the most "exposed" indoor positions. It is therefore important to represent periods of expected indoor and outdoor stay adequately in decision support dose modelling.

Naturally, the specific habit data is not available for each distinguished subset of the population (e.g., the people staying within a grid element of RODOS/ARGOS). This is recognised in ICRP publication 101 (2006), defining the exposed individual in relation to practical optimisation. Here it is stated that if needed, such "values may be derived from appropriate national or regional population data".

A particularly useful data source in this context originates from the European EXPOLIS project (see, e.g., Schweizer, 2004), where thousands of people in seven European cities (Athens, Basel, Grenoble, Helsinki, Milan, Oxford, and Prague), were studied with respect to their time budgets, and the hours they spent in various microenvironments. Similar information has also been generated in various American studies (e.g., Adair and Spengler, 1989; Boudet and Zmirou, 1997), and recently in a small study in Australia (Physick et al., 2011). The purpose of the EXPOLIS study was to generate information that could be applied in environmental pollution exposure studies, since there was a general lack of such data for European countries. However also a single earlier American study (Ott, 1989) had reported results of time diaries for a number of European cities, also based on quite comprehensive datasets, though not as detailed with respect to characterisation of the involved population. Of particular interest in the present context is information on time fractions spent in the outdoor environment. For the time spent outside the indoor environment, distinction was made in both studies between the time spent in transit (walking, biking, bus, train, underground) and the time spent in more stationary outdoor positions. It is worth noting that there is good correspondence 
between the two studies in the datasets for French and Czech cities (only these two countries were represented in both datasets), although the cities in these countries are actually not the same, and there are more than 10 years between the two studies. Also, there is correspondence between the fractions of time reported spent indoors at home in Osnabrück (Germany) and in a later, more comprehensive study of German homes (Brasche and Bischof, 2005). The results are also in reasonable agreement with results of newer, but smaller studies in Hertfordshire, UK, and Lille, France (Andersson, 2012). A fuller account of available data and discussion of influences of various parameters and aspects are given in Andersson (2012).

Within each dataset for a given location, there is a considerable variation, notably since the number of hours that a person works outdoors varies considerably. This should be represented in the values used for decision support. In relation to deterministic calculations of dose to the representative person, the ICRP's (2006) recommendation for the use of habit data is to use an "average value for the more highly exposed group or 95th percentile of appropriate national or regional data". Sufficiently detailed regional datasets to derive 95 th percentiles are only available for the EXPOLIS study. Since increasing the amount of time spent outdoors will in all cases increase the external dose, 95 th percentiles of the time fraction spent outdoors should be applied. Table I shows the relevant values extracted from EXPOLIS data for time spent outdoors and indoors $(2 \%$ have been added to the indoor budgets to account for the transit time spent in positions that are categorised as "indoor" with respect to shielding; the rest of the transit time is here accounted for as "outdoor"). As can be seen, the 95th percentile (as also the mean value; Andersson, 2012) varies only little between cities in different countries, and there does not seem to be a climatic correlation. Due to the little variation, European standard values of 0.75 and 0.25 may be applied for respectively indoor and outdoor time fractions.

Table I

Estimated 95th percentile time fractions spent indoors and outdoors in various European cities.

\begin{tabular}{lcc}
\hline & Time fraction indoors & Time fraction outdoors \\
\hline Helsinki & 0.73 & 0.27 \\
Athens & 0.74 & 0.26 \\
Basel & 0.73 & 0.27 \\
Grenoble & 0.79 & 0.21 \\
Milan & 0.77 & 0.23 \\
Prague & 0.73 & 0.27 \\
Oxford & 0.75 & 0.25 \\
\hline Average & 0.75 & 0.25 \\
\hline Standard deviation & 0.02 & 0.02 \\
\hline
\end{tabular}




\subsection{Indoor/outdoor air exchange rate for dose estimation in contaminated inhabited areas}

In the event of an incident leading to airborne contamination of inhabited areas, advice will, if at all possible, be issued to the public to stay indoors and close off air ducts and ventilation. It is thus expected that only natural ventilation through the building canopy will be at play, assuming there is sufficient time for the public to act in accordance with the recommendations. Natural ventilation rates for tightly constructed dwellings are typically of the order of 0.2 to $1 \mathrm{ACH}$ (air changes per hour, or simply $\mathrm{h}^{-1}$ ), whereas somewhat higher natural ventilation rates are observed in loosely insulated houses (typically in warmer climates).

There is not a whole lot of data available to describe the natural ventilation rates of the local building stock in different European areas. For some countries (particularly in Southern Europe) the reason for this may be that dwellings are rarely naturally ventilated, and also, building air tightness is generally analysed by applying a forced pressure of $50 \mathrm{~Pa}$ rather than reporting values at natural conditions (see, e.g., Ashmore and Dimitroulopoulou, 2009). Table II shows a summary of measured natural air exchange rates reported for different European countries. The datasets are varying in size, but at least some of them reflect a representative cross-section of the local building stock. It should be noted that things like temperature gradients, wind speed and terrain may influence the natural ventilation rate. For instance, it has been reported that for wind speeds above some $10 \mathrm{~m} / \mathrm{s}$, there is a pronounced increase in ventilation rate (by more than a factor of 2 between wind speeds of 10 and $25 \mathrm{~m} / \mathrm{s}$ ) if the house is leaky and positioned in open terrain (Mattsson, 2006). The effect of open windows is significant. According to a study by Daghigh et al. (2008), the ventilation rate in an office room will typically increase by a factor of 6 if a large window is opened and by a factor of 10 if two large windows are opened. If a door is also left open, the ventilation rate will be about a factor of 15 higher than that with all air ducts closed.

As Table II shows, there may locally be some variation, and a single high value in a limited dataset can significantly affect the mean value. This is for example the case for the Belgian dataset. The Finnish dataset also has a single value that is not at all in line with the rest, but this dataset is larger, and thus the influence on the average value is comparatively less. The French dataset contains an extremely high value that is probably an error (may be a case of forced ventilation in reality).

Considering the mean values in Table II, these agree well with the generic observation reported by the AIVC (1994) that natural air exchange rates are typically of the order of 0.2 to $1 \mathrm{ACH}$ in Northern Europe, and larger than $1 \mathrm{ACH}$ in Southern Europe. Based on the data in Table II, and other air tightness data, which cannot be applied directly, but still gives an impression of the relative air tightness of buildings in other European countries, it is proposed to distinguish between three geographical bands (North, Mid and South Europe) with respectively $0.5 \mathrm{ACH}$, 1.0 ACH, and 1.8 ACH (see Andersson, 2012, for further details). 
Table II

Results of a number of investigations of the ventilation rate, $\lambda$, under natural conditions in different countries (see Andersson, 2012 for data set references).

\begin{tabular}{|c|c|c|c|c|c|c|}
\hline Country & $\begin{array}{l}\text { Number } \\
\text { of buildings }\end{array}$ & $\begin{array}{c}\text { Types } \\
\text { of buildings }\end{array}$ & $\begin{array}{l}\text { Year of } \\
\text { reporting }\end{array}$ & $\begin{array}{l}\text { Mean } \lambda_{\mathrm{v}} \\
(\mathrm{ACH})\end{array}$ & $\begin{array}{c}\text { Min. } \\
\lambda_{\mathrm{v}}(\mathrm{ACH})\end{array}$ & $\begin{array}{l}\text { Max. } \lambda_{v} \\
(\mathrm{ACH})\end{array}$ \\
\hline Belgium & 18 & $\begin{array}{l}18 \text { houses, } \\
1 \text { industrial, } \\
2 \text { offices }\end{array}$ & 2011 & 1.3 & 0.2 & 3.2 \\
\hline Greece $^{+}$ & 39 & 39 houses & 2008 & 2.3 & 0.6 & 4.8 \\
\hline Netherlands & 218 & $\begin{array}{l}110 \text { houses, } \\
108 \text { apartm. }\end{array}$ & 1996 & 0.5 & 0.02 & 2.3 \\
\hline France & 644 & $\begin{array}{l}317 \text { houses, } \\
242 \text { apartm., } \\
85 \text { other }\end{array}$ & 2007 & 1.2 & 0.2 & 12 \\
\hline Norway & 17 & 17 houses & 2007 & 0.4 & 0.06 & 1.0 \\
\hline Finland & 128 & $\begin{array}{l}70 \text { houses, } \\
58 \text { apartm. }\end{array}$ & 2007 & 0.6 & 0.1 & 3.9 \\
\hline Germany & 27 & $\begin{array}{l}13 \text { houses, } \\
16 \text { other }\end{array}$ & 2006 & 0.4 & 0.04 & 1.7 \\
\hline Denmark $^{*}$ & 117 & 117 houses & 1997 & 0.4 & 0.2 & 1.0 \\
\hline Sweden $^{\square}$ & 410 & $\begin{array}{c}333 \text { detached } \\
\text { houses, } \\
33 \text { row houses, } 44 \\
\text { multi-storey flats }\end{array}$ & 2005 & 0.4 & $\mathrm{nr}$ & $\mathrm{nr}$ \\
\hline Portugal & 3 & 3 houses & 2009 & 1.4 & 0.7 & 1.8 \\
\hline Czech Rep. & 81 & "New" houses & 2010 & 0.8 & 0.04 & 4.2 \\
\hline $\mathrm{UK}^{\#}$ & 22 & $\begin{array}{l}17 \text { houses, } \\
5 \text { apartm. }\end{array}$ & 2006 & 0.5 & 0.2 & 1.0 \\
\hline
\end{tabular}

${ }^{+}$A study in a single Greek office building in 1996 reported a natural ventilation rate of between 1 and $3 \mathrm{ACH}$.

"An older Danish study from 1985 of 17 houses in Zealand gave an average of 0.54 ACH (min: 0.9; max: 2.14).

\# An older UK study from 1997 of 37 houses gave an average of $0.43 \mathrm{ACH}$ (min: 0.2; max: 0.7). In an other UK study from 1999 of 7 houses, ventilation rates between 0.2 and $1.6 \mathrm{ACH}$ were recorded. In a study of tightly sealed houses in Milton Keynes, natural ventilation rates between 0.2 and $0.5 \mathrm{ACH}$ were measured.

${ }^{a}$ An older Swedish study of 29 single-family homes reported a mean natural ventilation rate of $0.3 \mathrm{ACH}$, with a minimum value of $0.1 \mathrm{ACH}$ and a maximum of $0.8 \mathrm{ACH}$.

Note: "nr" in the above table means "not reported".

It is clear that the higher the ventilation rate becomes the higher will the indoor air concentration be. Thus to adequately protect the reference person, for whom habit data should be based on an "average value for the more highly exposed group or 95th percentile of appropriate national or regional data", 95th percentiles should be derived where possible. Only the datasets for The Netherlands, France, Finland, Denmark, Sweden, and the Czech Republic are large enough for this to make any sense, and for Sweden the data is not described in sufficient detail in the available material to allow this. The data for Denmark, Finland and The Netherlands suggest a 95th percentile in the region of $0.9 \mathrm{ACH}$ for the Northern European band, and the data for France and the Czech Republic suggest a value of some 1.8 or 2 $\mathrm{ACH}$ for the central band. For the southern band, too little data is available for any 
safe estimation, but since the 95th percentile is for the other bands about twice the mean, a 95th percentile value for the southern band might be expected to be of the order of 3.5 to $4 \mathrm{ACH}$.

\subsection{Some other needs for improvement of dose modelling in RODOS and ARGOS}

In recent years also other needs for improvement of the dose estimation capabilities of the European decision support systems have been identified. One of these relates to the definition of source terms. For instance concerning releases from nuclear power plants the focus has so far been on the amounts of radionuclides released in an accident of a given type. However, the volatility, and thus potential for release, of some radionuclides (e.g., of ruthenium) strongly depends on the release process (fire or explosion, and in particular oxidising conditions), and this needs to be taken into account. Also, the strontium released by the Chernobyl accident was found to have a solubility that reflected the release process. Much of the strontium deposited on soil remained in large particles for years (depending on soil $\mathrm{pH}$ ), where after a much increased environmental mobility was observed (Andersson, 2009). This sort of phenomenon needs consideration in countermeasure strategies based on estimates of residual dose. If the physicochemical forms of contaminants are better represented in models in relation to the scenario in question, essentially all dose contributions (including inhalation doses) will be better estimated.

An entirely different type of source term originates from malicious dispersion of radionuclides in connection with terrorist attacks. ICRP Publication 96 (2005) gives a series of recommendations in relation to such scenarios. Currently, RODOS and ARGOS can for a number of reasons not be applied for dose estimation in relation to malicious contaminant dispersion. One important reason is the different range of physicochemical forms of airborne contaminants formed by the dispersion process, leading to different deposition pattern and different environmental behaviour than that currently assumed in the European standard decision support systems (Andersson, 2009).

It should also be mentioned that a recent Nordic activity has led to identification of parametric updates of different parts of the radioecology model ECOSYS that essentially governs ingestion dose estimates in RODOS and ARGOS (Andersson et al., 2011). These findings could be applied to improve dose estimates.

\section{Conclusions}

On the basis of survey data for European countries, an improved parameterisation of the fractions of time spent by persons indoors and outdoors has been derived. These parameters do not appear to vary significantly within Europe. However, the overall time spent outdoors by a European reference person is significantly higher 
than what has previously been assumed for dose calculation in the European decision support systems, and this is important, since the only limited time spent outdoors often leads to a very large fraction of the external dose to persons living in a contaminated area. Based on measurement data for different European countries, a methodology was derived to distinguish between the air tightness of buildings. Natural ventilation rates were found to typically vary by a factor of 4 between different European regions. Depending on contaminant characteristics, this can lead to an equal variation in doses received from indoor contamination (including inhalation doses during the initial plume passage). This data for improvement of European decision support systems was derived as a part of the on-going project NERIS-TP, supported by the European Commission. A number of other needs for parametric improvement for dose calculations in the decision support systems were briefly discussed.

\section{REFERENCES}

Adair J. H., Spengler J. D. (1989) Time activity and exposure assessment: the six city indoor air quality experience. In: 82nd Annual Meeting and Exposition of the Air and Waste Management Association (Paper No. 89-100.5), Anaheim, CA.

AIVC (1994) An Analysis and Data Summary of the AIVC's Numerical Database. Air Infiltration and Ventilation Centre (AIVC) Technical Note.

Andersson K.G. (ed.) (2009) Airborne radioactive contamination in inhabited areas, Book Series Radioactivity in the Environment vol. 15 (series editor: M.S. Baxter), Elsevier, ISBN 978-0-08-044989-0, ISSN 1569-4860.

Andersson K.G. (2012) Area-specific indoor parameterisation for RODOS and ARGOS, Draft report on a task under Deliverable D2.3 of the NERIS-TP project, Euratom for Nuclear Research and Training Activities: Fission 2010: 269718.

Andersson K.G., Nielsen S.P., Thørring H., Hansen H.S., Joensen H.P., Isaksson M., Kostiainen E., Suolanen V., Pálsson S.E. (2011) Revision of deposition and weathering parameters for the ingestion dose module (ECOSYS) of the ARGOS and RODOS decision support systems, J. Environ. Radioactiv. 102, 1024-1031.

Ashmore M.R., Dimitroulopoulou C. (2009) Personal exposure of children to air pollution, Atmos. Environ. 43, 128-141.

Boudet C., Zmirou D., et al. (1997) Subjects Adapt Time-Activity Patterns during Participation in a Personal Exposure Assessment Study. In: 7th Annual Meeting of the International Society of Exposure Analysis, Research Triangle Park, NC.

Brasche S., Bischof W. (2005) Daily time spent indoors in German homes Baseline data for the assessment of indoor exposure of German occupants, Int. J. Hyg. Envir. Heal. 208 (4), 247-253. 
Daghigh R., Adam N.M., Sahari B.B., Sopian K., Alghoul M.A. (2008) Influences of air exchange effectiveness and its rate on thermal comfort: naturally ventilated office, J. Building Physics, 32 (2), 175-194.

ICRP publication 96 (2005) Protecting people against radiation exposure in the event of a radiological attack, Ann. ICRP 35 (1).

ICRP publication 101 (2006) Assessing dose of the representative person for the purpose of radiation protection of the public and the optimisation of radiological protection, Ann. ICRP 36 (3).

Mattsson B. (2006) The influence of wind speed, terrain and ventilation system on the air change rate of a single family house, Energy, 31, 719-731.

Meckbach R., Jacob P., Paretzke H.G. (1988) Gamma exposures due to radionuclides deposited in urban environments. Part I: Kerma rates from contaminated urban surfaces, Radiat. Prot. Dosim. 25 (3), 167-179.

Ott W.R. (1989) Human activity patterns: a review of the literature for estimating time spent indoors, outdoors, and in transit. In: proceedings of the Research Planning Conference on Human Activity Patterns, Las Vegas, NV, EPA National Exposure Research Laboratory, EPA/600/4-89/004.

Physick W., Powell J., Cope M., Boast K., Lee S. (2011) Measurements of personal exposure to $\mathrm{NO} 2$ and modelling using ambient concentrations and activity data, Atmos. Environ. 45, 2095-2102.

Schweizer C. (2004) EXPOLIS annex, http://www.ktl.fi/expolis/files/FR_WP1.pdf 